\title{
DIE VROU EN DIE KERKLIKE AMPTE
}

Die aangeleentheid waaroor dit in hierdie artikel gaan, het veral die afgelope twee dekades aan die orde gekom oor 'n baie breë front van sowel teologiese diskussie as "amptelike" kerklike besinning.

In eie midde hier in Suid-Afrika, en veral binne die Gereformeerde Kerk (die Hervormde Kerk het reeds kanale geopen vir vrouelike diakens, en die saak het op die Algemene Sinode van die Nederduits Gereformeerde Kerk in 1974 by wyse van' $n$ rapport ter tafel gekom) is die aangeleentheid in die breë gesien nog heel rustend. Dit sal egter onvermydelik in diskussie moet kom. Twee artikels van prof B Spoelstra in In die Skriflig (1971) was 'n stimulerende inleiting tot so 'n disklissie, wat, eienaardig genoeg, skynbaar net daar weer opgedroog het.

Wat hier gebied word is dus, ook wat myself betref, geen finale woord nie, maar neem veeleer die vorm aan van enkele stellings, meerdere vrae, en 'n verkenning van sekere Skrifgegewens met die oog op koersgewing aan 'n verdere diskussie wat hopelik sal volg.

\section{GRONDSTELLING OOR DIE AKTIWITEIT VAN DIE VROU IN DIE KERK}

Terwyl dit onverantwoord sou wees om te meen om oor alle aspekte van hierdie vraagstuk afdoende antwoorde of besliste standpunte te hê, wil ek begin met 'n stelling wat ek bereid is om met krag en vrymoedigheid enduit te stel en te verdedig: In die Nuwe Testamentiese tyd het vroue in die aktiewe geestelike dienswerk van die kerk'n plek gevul van so 'n aard en omvang dat dit moet dien as 'n getuienis teen die kerk van alle latere eeue!

\section{TOELIGTENDE STELLINGS}

1.1. In die dienswerk van die vroegste kerk beklee die vrou 'n aktiewe geestelike plek in radikale kontras met die Joodse sinagoge- en tempeldiens, waar sy nie veel meer as net geduld was nie. Die vrye Joodse man moes volgens Rabby nse voorskrif daagliks dank: Geprese is U, o God, dat U my nie geskape het as 'n heiden, as 'n slaaf of as 'n vrou nie" ( $p$ Ber 13 b; b Men 43 b).

1.2. In die dienswerk van die vroegste kerk beklee die vrou 'n aktiewe geestelike plek in radikale kontras met 
die heidense kulture, waar sy wel 'n prominente rol gespeel het, maar só dat sy totaal gedegradeer is tot 'n seksoffer in die prostituut-priesteressedom.

1.3. So was die vroegste kerk die omringende samelewing vér vooruit in sy konkreet-geestelike bevryding van die vrou.

Sekere kwelvrae tree na vore vanuit hierdie grondstelling: Het die kerk deur die eeue die samelewing vóór gebly? En is ons eie kerke die samelewing nog vóor in die bevryding van die vrou om haar volwaardige aktiefgeestelike diensroeping te kan vervul? Terwyl die wêreld die vrou emansipeer, maar by alle emansipasie haar tog weer grootliks terugdwing in die plek wat sy in die heidense kultusse gehad het, $d$ w s haar degradeer tot'n seksoffer - in hoeverre het die kerk deur die eeue toegelaat dat daar ten opsigte van die plek van die vrou in die kerk teruggeval word in die ou Judaisme?

2. 'N KORT PRINSIPIËLE ORIËNTERING: DIE POSISIE VAN DIE VROU IN DIE LOOP VAN DIE OPENBARINGSGESKIEDENIS

Uiteraard kan hier net enkele hooflyne getrek word.

\subsection{SKEPPINGSGELYKHEID EN}

SKEPPINGPRIMAAT

Die Skrif leer duidelik dat God by die skepping twee principia in die verhouding van man en vrou openbaar: gelykheid en primaat.

Gelykheid. Gn 1:26-29: God maak die mens man én vrou, en maak beide na sy beeld en gelyken is. Hulle word medebeelddraers. Maar God gee ook aan man en vrou tesame die opdrag om te heers oor sy skepping. Hulle word dus ook mede-heersers!

Dit mag daarom nooit so voorgestel word asof dit teen die wese van die vroulike geslag is, of teen 'n "skeppingsordinansie" ingaan dat die vrou ook mag heers of regeringsfunksies mag vervul nie. Tewens dit is ook onteenseglik haar eindbestemming in die heerlikheid saam met die man (Mt 19:28-29; Op 22:5).

Primaat. Gn 7, 18 en 23: God het die man eerste geskape en die vrou uit die man. So word die vrou dan ook geskape as 
"'n hulp wat by hom pas". Die man is dus in verhouding tot sy vrou geskape as primus inter pares. Hierop beroep die apostel Paulus hom herhaaldelik, in I Kor 11:8-12; Ef 5:31; I Tm 2:13.

\subsection{SONDEVALSTRAF EN GENADIGE ORDEREËLING IN DIE SONDEBEDELING}

Wanneer die vrou die slang gehoorsaam en ook haar man versoek om te sondig, kom die straf van God oor haar, wat ook hulle onderlinge verhouding in die sondebedeling raak: Gn 3:16: "Na jou man sal jou begeerte wees ... en hy sal oor jou heers." Hier moet egter goed opgelet word dat dit nie 'n strafreëling van heerskappy van die manlike geslag oor die vroulike geslag is nie, maar van heerskappy van "jou man" oor sy vrou! En verder is dit duidelike dat hierdie wcord van God veelmeer is as blote straf - dit is ook 'n genadige ordereëling van God binne die versteurde harmonie wat die sonde gewerk het in die menseverhoudinge ( $\mathrm{vgl}$ ook die getuienis van $\mathrm{Rm} 13$ ten opsigte van die doel van die owerheidsgesag).

Van hierdie heers-opdrag van die man oor sy vrou, het die mens egter in sy sonde-dekadensie gemaak 'n wrede tirannie van die man oor die vrou; en bowendien dan nog: van die manlike geslag oor die vroulike geslag.

\subsection{GENADIGE ORDEREËLING IN DIE OU TESTAMENTIESE WETGEWING EN OPENBARING}

Teenoor die heidense verslawing van die vrou tot blote besitting van die man; waar die man vry was om te hoereer waar en soos hy wil, maar terselfdertyd die reg van doodstraf oor die vrou had as sy egbreuk sou pleeg; waar die vrou in die heidense kultusse wel dikwels 'n prominente plek had maar dan gedegradeer is tot seksoffer aan die vrugbaarheidsgodinne (Astarte, Aphrodite), kom die Godsopenbaring aan Israel, nie rewolusionêr-omverwerpend nie, maar opvoedend-remediërend: in die vyfde gebod word op unieke wyse vader én moeder in een asem genoem, en word teenoor beide gelykelik en gelyke eer vereis. Vgl ook Lv 10:9 en Spr 30:17. In die sewende gebod word, op unieke wyse 'n omvattende "jy"-gebod vir die huwelikstrou gegee. "Jy", hetsy man of vrou, "mag nie egbreek nie". Vgl ook die nadere uitwerking en die konsekwent-gelyke toepassing hiervan in Lv 20:10 vv, Dt 22:23- 
26. Vroue verkry ook die besondere reg tot erfgrond en grondbesit ( $\mathrm{Nm}$ 27:1-11), en 'n eie staanplek selfs in die openbare lewe: Debora as profetes en rigter, en die deugsame vrou van $\mathrm{Spr} 31$ in die bedryfslewe.

\subsection{BEVRYDING EN HERGTEL VAN DIE VROU IN CHRISTUS}

\subsubsection{Jesus se optrede}

Hoewel daar breedvoerig gehandel kan word oor Jesus se optrede teenoor vroue en die plek wat vroue in sy wonders en prediking inneem, wil ek net enkele relevante sake aanstip:

Jesus verkondig die evangelie van die lewe in die openbaar aan 'n vrou - die Samaritaanse vrou van Jh 4; vroue verkry eweneens 'n plek in sy dissipelkring (Lk 8:1-3; Mt 27:55); vroue word onvoorwaardelik 'n gelyke plek toegesê in die huisgesin van Jesus Christus (Mt 12:50); vroue word die eerste getuies en verko ndigers van die opstanding van Christus (Mt 28:1-10 par)!

\subsubsection{Die vrou in die Vroeë Kerk}

Gelykheid is hier ondubbelsinnig duidelik verkondig én beoefen. Beslissend is en bly die uitspraak van G1 3:27-28: "want julle almal wat in Christus gedoop is, het julle met Christus beklee. Daar is nie meer slaaf of vryman nie, daar is nie meer Jood of Griek nie, daar is nie meer man of vrou nie; want julle is almal een in Christus Jesus." Hierdie uitspraak is duidelik, en onteenseglik ook doelbewus duidelik, in lynregte teenstelling tot die Joodse ongelykheidsleer wat voor God die Jood verhef het bo alle nieJode; die vryman bo die slaaf; en die man bo die vrou.

Hoedat hierby gelykheid en eenheid van man en vrou voor God in Christus binne die Kerk van Christus werklikheid word en ook gekonkretiseer moet word, kom in die Skrifte van die Nuwe Testament telkens weer na vore. Ek wil dit soos volg saamvat:

i. Die vrou is mede-erfgenaam van die genade van die lewe, I Pt 3:7.

ii. Die vrou is mede-lidmaat van die gemeente, Hd 1:14; Ef 5:22; Kl 3:18.

iii. Die vrou is ook mede-arbeidster in die gemeente, $\mathrm{Hd}$ 18:18, 26; Rm 16:3-4, 7, 12, 15; I Kor 11:11-12; Tit 2:3-4. 
So vind ons dan, in en deur die Christus-bevryding, die vrou opnuut as volwaardige lid van die volk van God; volkome lidmaat van die liggaam van Christus - en dus iemand wat 'n onmisbare funksie in daardie liggaam het wat nie verag mag word nie, en vir wie nie geseê kan word: ons het jou nie nodig nie (vgl I Kor 12:4-11, 12, 14-25 maal veral verse 21-25!). Die gawes van die Gees wat $H y$ aan vroue skenk mág nie in die Kerk verwaarloos word of op non-aktiwiteit geplaas word nie! En - vroue ontvang ook wel méér as die algemene vrug van die Gees (Gl 5:22); méér as die gawe van gasvryheid (Lidia, Hd 16:14-15); meer selfs as gawe tot diensvaardigheid en liefdesdiens (Dorkas, Hd 9:36-39). Daar is óók vroue wat die gawe van profesie en van didaskalia (Tit 2:3 en Hd 18:26) ontvang.

\section{Andersheid gehandhaaf}

Die verlossingswerk van Christus hef die sondige ongelykheid op, maar nié die skeppingsprimaat van die man nie, en ook nié die genadige ordereëling van God vir hierdie sondebedeling nie (net soos die owerheidsgesag nie deur Christus opgehef is nie).

In die briewe van Paulus en Petrus word dit herhaaldelik benadruk: by haar heerlike vryheid in Christus, haar "geen onderskeid"-posisie voor God en sy gemeente, moet die vrou aan haar man (let wel: aan háár man) onderdanig wees en nie oor hom heers of wil heers nie.

Dit is baie belangrik om daarop te let dat die apostel Paulus vir hierdie sondebedeling hom nie beroep op konvensie nie; nie op die eie-tydse siening van die plek van die vrou nie - daarvoor was die Kerk die wêreld ten ene male te ver voor! Maar hy beroep hom steeds op God se openbaring in die begin: eerstens op die sondestraf en genadige ordereëling van God, bv in I Tm 2:14; tweedens op die man se Godgegewe skeppingsprimaat, bv in I Kor 11:8,9 en I Tm 2:13.

Dit moet uiteindelik by oorweging van die relevansie van Skrifuitsprake oor "vrou en amp" deeglik in gedagte gehou word. Mens vind naamlik sowel by WRK-rapporte oor die aangeleentheid as by die deputate-rapporte van die GKN van 1965-66 en 1967-68 dat die absolute geldigheid van Gl 3:28 vir alle tye welsterk benadruk word, terwyl by voorbeeld I Kor 11:13-16, I Kor 14:34-38 en I Tm 2:1115 deur die WRK ongekwalifiseerd en deur die GKNdeputate op gekwalifiseerder wyse as "tydgebonde" gedevalueer word. 


\section{AMP, AMPTE EN GAWES IN DIE NUWE TESTAMENT}

Hoe kardinaal die vraag na die suiwere ampsbegrip, en besonderlik na die verhouding van amp en Geestesgawe. is by die ondersoek na die regte verhouding vrou-ampte, blyk baie duidelik uit die volgende:

3.1. By behandeling van eksegetiese gegewens rakende die vraagstuk merk die WRK se Committee dealing with questions of the Department on Faith and Order in 'n rapport van Febr 1964 op:"These exegetical considerations apply equally to two larger but related questions: the message of the Bible regarding the Christian ministry and the meaning of ordination ... this committee expresses its hope that discussions of the ordination of women will be carried on in close connection with the discussions of the ministry and of ordination , ,." (a w, pp 7,8).

3.2. Die deputaten voor onderzoek naar de plaats van de vrouw in de dienst der kerk van die GKN sê in hulle rapport aan die Sinode van Amsterdam 1967-68 onder andere: "Wel menen deputaten te moeten ingaan tegen de scherpe scheiding, welke verschillende tegenstanders van de vrouw in het ambt maken tussen ambtelijke dienst en nietinstitutair geregeld charismatisch optreden, en nog enige opmerkingen te moeten maken in verband met de onklaarheid die er blijkbaar bij velen heerst omtrent de vraag, wat onder ambt dient te worden verstaan ... Terecht stellen de Kerkeraad van Donkerbroek ... de vraag, of het probleem rond de vrouw in het ambt niet voor een groot deel voortkomt uit een overtrokken, niet bijbels gefundeerd ambtsbegrip" (a w, p 534-35).

3.3. Die GES behandel inderdiad die saak van The Ministry of Women slegs as in onderdeel van sy ondersoek na Office in the New Testament (vgl Acta. The Reformed Ecumenical Synod, Sydney 1972 pp 167-204).

Vanselfsprekend kan die wese van die amp in die Nuwe Testament hier nie uitvoerig behandel word nie. en ek voel my daartoe ook nie bevoeg nie. Ek volstaan dus met enkele stellings en enkele vrae met die oog op diskussie en verdere ondersoek. 
Stelling 1

Die ampte is volgens Nuwe Testamentiese getuienis alleen te omskryf as "bedieninge, diakoniai, van Christus in en aan sy gemeente"

Die drie wesenselemente van die amp moet gelyktydig en gelykelik vasgehou word, anders word die ampsbegrip verwring en kom telkens die mens in die ampsbeskouing, ampswerk en ampsverkiesing op die troon - of spesifiek met betrekking tot ons onderwerp gestel: dan begin dit gaan om vroueregte, vervlak dit spoedig tot argumente soos: waarom moet vroue met soveel bekwaamhede uitgesluit wees; of: dit is vernederend vir die vrou; of: die man se posisie word bedreig ...

Stelling 2

Ampte en Geestesgawes mag nie vereenselwig word nie, en mag ook nie geskei word nie.

2.1. Die amp mag nooit sonder gawes bedien word nie. (Hoe dikwels maak kerkrade hulle hieraan skuldig!) Mans (of vroue) sonder die gawes mág dus nie verkies word nie.

2.2. Andersyds: "Gawe" is nog nie "amp" nie. Die besit van Geestesgawes in die Kerk gaan veel wyer en kom veel talryker voor as wat daar ampsdraers is of kan wees (vgl o a Hd 1:12 vv; Hd 6). Mans met die nodige gawes het daarmee nog nie die "reg" dat hulle in die diakonia gestel móét word nie. Die feit, dus, dat vroue ook geestesgawes ontvang, is nog nie per se 'n bewys dat hulle ook tot die diakoniai verkies moet word nie.

2.3. Die gawes kan ook sonder en buite die amp om bestaan en funksioneer. Ons kan nie ernstig genoeg waarsku teen die inperking van die beoefening van gawes wat nodig is vir 'n bepaalde amp uitsluitlik deur diegene wat in die amp staan nie! By voorbeeld, asof slegs diegene wat in die leeramp staan die gawe van didaskalia kan of mag beoefen. Dit lei tot 'n onskriftuurlike hiërargie wat byvoorbeeld profesie ver-amptelike en die gawe van profesie in die gemeente versmoor.

Weë en kanale met dus gesoek en geskep word vir die gebruikmaking van en stimulering vir die dienswerk van Geestesgawes ook buite die ampte - ook en besonderlik die gawes wat aan vroue gegee word. 
2.4. Die 1965-66 deputate van die GKN waarsku teen 'n "scherpe scheiding" tussen amp en charisma, wat volgens hulle sou lei tot verset teen vroue in die amp, maar hulle verval, in hul ywer om die vrou wel in die amp te stel, in die ander uiterste wanneer hulle oor die verhouding tussen amp en gawe sê: "Deze vrouwelijke diensten (in de N T gemeenten - JCC) hebben in eerste instantie een spontaan fungerend charismatisch karakter. Maar de institutioneel geregelde diensten - die wij 'ambten' plegen te noemen - staan in geen enkel opsicht daartegenover ... Theoretisch gesproken kan dan ook elke charismatische dienst uitgroeien tot een institutioneel geregelde ' ambtelijke' dienst, en het is betrekkelijk willekeurig, dat 'het ambt'onder ons beperkt is gebeleven tot enkele speciale leidinggevende functies." (Bijlagen tot die Acta, 1865-66, p 132 - kursivering van my, J C C). Tewens, vanaf die begin van die "ampsontwikkeling" in die Nuwe Testament word gawe en amp deeglik onderskei (hoewel nooit geskei nie): te midde van al die gawes onder die gelowiges, stel Christus ampte daar waarvoor van die begin af en deurgaans nodig blyk te wees: (i) Goddelike roeping, (ii) konkrete verkiesing of aanwysing; (iii) behoorlike opdraggewing; (iv) openlike ordening of bevestiging - vgl Mk 3:13-14; Hd 1:20-26; Hd 6:2-6; Hd 14:23; Tit 1:6-9.

\section{Stelling 3}

Die probleme waarom dit gaan word myns insiens grootliks verduister deur die gebruiklike veralgemening van die probleem tot: die vrou en/in die amp. Die probleemstelling behoort te lui: die vrou en/in die afsonderlike ampte. Immers, so iets soos "die amp" bestaan nie in die Nuwe Testament nie.

Ampte, diakoniai, is bedieninge van Christus aan die gemeente, en daarom, hoewel gelykwaardig, tog elk wesenlik verskillend van die ander, elkeen met sy eie aard en eie nodige gawes. Dit kan dus goedskiks moontlik wees dat die vrou vir een gepaalde amp nie oorweeg mag word nie, maar vir'n ander tog wel deeglik oorweeg moet word.

Moet daar nie by die oorweging en navorsing van hierdie saak finaal losgekom word van die oorvereenvoudigde benadering van die Nuwe Testamentiese ampte as blote verlengstukke van die Ou Testamentiese "ampte", sodat 
die ouderling dan koning, die leerouderling profeet en die diaken priester sou wees nie? Word ons nie dikwels in ons standpuntvorming meer deur hierdie vooropgesette benadering beïnvloed as deur die werklike Nuwe Testamentiese getuienis aangaande die vrou en die ampte nie?

\section{SKRIFGEGEWENS WAT BLYKBAAR DIE PROBLEEM VAN DIE VROU EN DIE AMPTE MEER DIREK RAAK - EN HUL RELEV ANSIE VIR DIE KERK VANDAG.}

Vooraf is die volgende opmerking nodig: As ons kom by die vraag na die relevansie van Skrifwoorde vir vandag, ook op die onderhawige terrein, gaan ek uit van wat myns insiens die enigste geldige standpunt is, te wete dat die Skrif alleen die norm is vir sy eie normatiwiteit. Daarom mag ten opsigte van Skrifwoorde oor die plek van die vrou in die kerk nog die norm geld van: in die moderne samelewing is dit of dat nie meer aanvaard of aanvaarbaar nie en daarom is die Bybelse uitsprake hieroor tydgebonde; nog die norm van: daar staan dit nou eenmaal so geskry we en klaar. Ter illustrasie van lg bedoeling neem ek as voorbeeld I Kor 7 waar Paulus die gemeente so duidelik afraai om te trou of hulle kinders te laat trou. Is dit nou, omdat dit so geskrywe staan in die Bybel, ewig en oral geldend? Nee, want Paulus sê self dit is 'n woord vir die Korinthiërs met die oog op die tyd van vervolging wat op hande is (verse 26, 28-35).

\subsection{DIE VROU EN DIE AMPTE VAN LERING EN} OPSIG.

Die mees kardinale Skrifgedeeltes in hierdie verband bly die volgende:

4.1.1. Uitsprake wat die moontlikheid skynbaar afwys. I Kor 14:33-40: Ek vertaal vers 33(b), 34-35 en 37 volgens die UBS-teks se lesing:"Soos in al die gemeentes van die heiliges moet die vroue in die gemeentes swyg; want dit is hulle nie toegelaat om te spreek (lalein) nie, maar om onderdanig te wees, soos die wet ook sê. Maar as hulle iets wil leer (mathein), laat hulle tuis hulle eie mans (tous idias andras) vra, want dit is lelik vir' $n$ vrou om in die gemeente te spreek... As iemand meen dat hy 'n profeet of iemand met ' $n$ Geestesgawe is, moet hy erken dat wat ek aan julle skryf, 'n bevel van die Here is." 
Dit blyk uit vers 37 met welke erns Paulus dit sê wat hy hier skryf. Elke moontlike houding van "dit is maar Paulus se siening gewees" word by die wortel afgesny.

Dit is 'n ernstige vraag of daar met hierdie woord omgegaan kan word op die wyse van die genoemde rapport voor die Sinode van die GKN wat die standpunt inneem: die beginsel dat die vrou aan haar eie man onderdanig moet wees, is ewiggelddend, maar die wyse waarop, die hoe, naamlik deur te swyg in die gemeente, dié is tydgebonde.

Aan die ander kant is dit gebiedend noodsaaklik om deeglik rekening te hou met die vraag of Paulus dit hier het oor die vroulike geslag (woman) of oor die getroude vrou (wife). Myns insiens pas sowel Spoelstra (art. in In die Skriflig) as die rapport by die GES (1972) I Kor 14 te gemaklik toe asof dit sonder meer die vroulike geslag raak. Die "hai gunaikes" van vers 34 word immers uitdruklik nader gekwalifiseer deur vers 35 wat duidelik maak wie hulle is en ook waarom hulle moet swyg in die gemeente: omdat hulle getroude vroue is en dus hul mans het vir wie hulle tuis kan vra. Dáárom moet hulle nie met hulle vrae in die openbare vergadering kom asof hulle mans deur hulle nie eerbiedig word nie. Die sg "swyggebod" van I Kor 14 raak dus die getroude vrou, en dit is nie sommer vanselfsprekend dat dit op die vroulike geslag toegepas kan word nie.

I Tim 2:11-15 word gewoonlik, en tereg ook, nou verbind aan I Kor 14:33-40. Ook hier word die vrou beveel om haar in stilheid te laat onderrig en onderdanig te wees. Daarby word nou nog gevoeg: "Ek laat'n vrou nie toe om te leer (didaskein) nie, nog om gesag oor die man te voer nie" (vers 12). Die leraarstaak en gesagbekleding oor die man in die gemeente word as 'n algemeengeldende reël (epitrepo - praes ind) ontoelaatbaar gestel. Hier skyn, aansluitend by I Kor 14, sowel die amp van lerende ouderling as die ouderlingeamp vir "die vrou" nie toeganklik te wees nie.

Ook is hier nie so eksplisiet net van die getroude vrou sprake nie. Waar I Kor 14 die swye van die getroude vrou in die gemeente grond op die feit dat die man in die huwelik hoof van die vrou is, fundeer Paulus in I Tm 2 sy verbod op die skeppingsprimaat van die man (vers 13) en op 
die straf en ordereëling van God na die sondeval dat die man oor die vrou sal heers (vers 14). Hierdie laaste fundering open myns insiens tog sterk die moontlikheid dat Paulus met gunê en anêrook in I Tm 2 bedoel die getroude vrou en háar man, 'n rigting waarin vers 15 ook by implikasie kan wys. Hoewel Ridderbos, sonder Beredenering, so 'n interpretasie "te tedentieus" noem (de Pastorale Brieven, Commentaar op het Nieuwe Testament, Kampen 1967 p 82), is ek oortuig dat hierdie verstaansmoontlikheid minstens ernstige oorweging verdien. Die wyse waarop Paulus sy reëling hier in die Skrif self fundeer, sluit alle reg uit van enige wegredenering van I Tm 2:11-15 as sou dit 'n bloot tydgebonde reëling wees volgens eerste eeuse sosiale praktyke.

Die argument word meermale geop per dat ons nêrens uitdruklik lees van vroulike ouderlinge of leerouderlinge nie, ja, dat Jesus tog ook nie vroulike apostels geroep het nie. Dit is uiteraard selde 'n deurslaggewende of selfs sterk argument - 'n argumentum e silentio.

\subsection{UITSPRAKE WAT MOONTLIK 'N DEUR OPEN?}

Voorop staan die bekende I Kor 11:3-16 oor die vrou en die bedekking op die hoof. Hier word sekere voorw aardes (of beperkinge) gestel wanneer 'n vrou in die gemeente wiI bid of profeteer. Die onomstootlike feit bly egter dat die reg en vryheid van die vrou om wel in die gemeentevergadering te bid en te profeteer hier aksiomaties gestel word - dit gaan nie oor die "Of" nie, maar slegs oor die "hoe"! Neem hiermee saam die bekende profesie van Joël soos aangehaal en toegepas op die Nuwe Testamentiese Kerk in Hd 2:17-18: "En in die laaste dae, spreek God, sal Ek van my Gees uitstort op alle vlees, en julle seuns en dogters sal profeteer ... En ook op my diensknegte en diensmaagde sal Ek in dié dae my Gees uitstort, en hulle sal profeteer." Dan is dit duidelik dat profesie en gebed, ook in die gemeentelike samekoms vir die vrou nie uitgesluit is nie, ook nie vir die getroude vrou om wie dit primêr in I Kor 11 gaan nie. Daarby moet egter dadelik opgemerk word dat in genoemde Skrifgedeeltes nog geen bewys lê vir amptelike woordbediening deur die vrou nie. Tewens, plaas mens I Kor 14 en I Tm 2 langs Hd 2 en I Kor 11 dan is dit vrywel duidelik dat die Skrif 'n besliste onderskeid maak tussen charismatiese profesie (en gebed) en amptelike lering of prediking: terwyl didaskalia deur die (getroude) vrou in die gemeentelike samekoms met beslistheid verbied word, om enige gesagvoer- 
ing oor die man te voorkom, word profesie en gebed, op voorwaarde dat dit só geskied dat die getroude vrou haar man as hoof nie oneer aandoen nie, as aksiomaties aanvaar.

Ook Tit 2:3-4 kom hierby in aanmerking waar van die bejaarde vroue gesê word hulle moet wees "leraresse van wat goed is (kalodidaskalous) sodat hulle die jong vroue kan leer om ..." Hier word dus selfs 'n didaskaliese of lerende funksie aan vroue opgedra, maar dan nie in die gemeentelike samekoms of in 'n "amptelike" sin nie.

Laastens moet hier herinner word aan die veelvuldige verwysings in Paulus se briewe en in Handelinge na sovele vroue wat met hom in die sending en in gemeentes vrugbaar saamgewerk het in die Evangelie: Priscilla, wat saam met haar man Aquila "die weg van God uitlê" (Hd 18:2, 18, 26) en 'n medewerker van Paulus in Christus Jesus is (Rm 16:3), en in meeste gevalle selfs vóór haar man genoem word; Euodia en Sintiche, "vroue wat met my saamgestry het in die Evangelie (Fl 4:3); Maria, "wat baie vir ons gearbei het" ( $\mathrm{Rm}$ 16:6); Trifena en Trifosa, "vroue wat in die Here arbei" (Rm 16:12); Persis, "die geliefde vrou, wat baie in die Here gearbei het" (Rm 16:12), e a. Dit is duidelik watter besonder prominente plek vroue beklee het op Paulus se sendingreise en in die vroeë jare van sy gemeente-opbou. Terselfdertyd vind ons egter in genoemde uitsprake geen werklike aanduiding dat enige van hierdie vroue "amptelike" Woordbedienaars was nie.

Let wel, die dienswerk van ouderlinge kom nêrens waar van die vroue sprake is, hoegenaamd in die gesigsveld nie!

\subsection{MAAR WAT VAN DIE DIAKENAMP?}

Terwyl die G K N met klaarblyklike groot haas, nieteenstaande proteste en waarskuwinge van susterkerke die ampte in die algemeen oopgestel het vir die vroulike geslag (vgl o a Acta 1967-68 p 285), het die GES, sonder dat die leraarsamp of ouderlingeamp nog enigsins ernstig oorweging geniet, ten opsigte van die vrou in die diakenamp versigtiglik begin beweeg: "that member churches should be cautious to proceed in the direction of the entrance of women into the diaconal office. Each church must make its own responsible evaluation of its situation and decision" (Acts of the Reformed Ecumenical Synod, 1972 p 60). 


\subsubsection{Teksgetuienis?}

I Tm 3:11: Dit is die opvallende teksvers in die so-bekende hoofstuk oor die vereistes vir ampsdraers: "Netso moet die vroue waardig wees, geen kwaadsprekers nie, nugter, betroubaar in alles." Die vers kom voor binne die konteks van verse 8-12 wat oor die diakens handel. Die kardinale vraag is dan wat hier bedoel word met gunaikas, "vroue": is dit "vroulike diakens" of is dit "die vroue van die diakens"? (Daar is ook wel ander interpretasies aan die hand gedoen wat minder waarskynlik is - vir'n oorsig oor die verskillende verklarings wat aangebied is, vgl $\mathrm{H} \mathrm{N}$ Ridderbos, De Pastorale Brieven, pp 98-99). Wanneer gt $! \leqslant t$ word op die strukturele opbou van 3:1-13 voel mens gedwonge om versigtiglik-beslis te kies vir die interpretasie: gunaikas = vroui. 're diakens. Immers, nieteenstaande die voorkc ms van punte aan $\mathrm{d}^{\prime} e$ einde van verse 6,9 en 10 bly die dei oun van vers 2 die hele perikoop tot en met vers 11 beheers, en kry mens die volgende heg-ge struktureerde drie-eenheidsperikoop:

$$
\begin{gathered}
\text { dei oun - ton episkopon (2-7) } \\
\text { - diakonous hosautos semnous (8-10) } \\
\text { - gunaikas hosautos semnas (11). }
\end{gathered}
$$

Dit toon duidelik dat oor hierdie "vroue" dus op presies gelykwaardige en doelbewuste paralelle wyse gespreek word as oor die ouderlinge en oor die manlike diakens en so geplaas word binne die "ampskader" van 3:1-13. Die opvolging met die woord diakonoi in vers 12 stel dit bo twyfel dat die "vroue" net betrek word by die diakenamp en nie by die episkopos-amp nie. Die leser word verder verwys na die argumente van Ridderbos (idem) waarmee ons volkome instem.

Rm 16:1: "Ons beveel by julle aan ons suster Phoebe, synde 'n diakonos van die gemeente in Kenchreë... (2b) ... want sy was vir baie, ook vir myself, 'n beskermvrou (steunpilaar)". Hier is die crux natuurlik hoe mens diakonos moet verstaan: in tegniese sin, $d w$ w "suster Phoebe, synde 'n diaken van die gemeente ...", of in 'n onbepaalde, algemene sin: "suster Phoebe, 'n dienares ..."

Die rapport voor die GES 1972 is baie uitgesproke: "Arguments based on Rom 16:1, that 'Phoebe was diakonon of the church at Cenchre-ae' indicates an official function, carry no weight at all. 'Deacon' is here not used 
as a technical term. It has the wider meaning of servant" (Acts, p 200). Geen eksegetiese gronde vir dié bewering word egter aangevoer nie, behalwe 'n heel arbitrêre verwysing na die gebruik - nie van diakonos nie! - maar van diakonia in $\mathrm{Rm} \mathrm{12:7}$ en $\mathrm{I}$ Th 3:2.

Daarteenoor dra die volgende grammatiese feite gewig:

(1) In stede van die werkwoord diakonein, wat nadruk sou laat val het op Phoebe se aktiwiteit van diens in die breër sin van die woord, word die statiese ousan diakonos gebruik wat veeleer Phoebe se "stand" of "status" in die gemeente beklemtoon.

(2) Die manlike woord diakonos val op, terwyl 'n breë keuse van vroulike dienares-begrippe in Grieks voorhande is. Dat die manlike woord van hierdie vrou gebruik word, skyn tog te dui op 'n sterk tegniese gebruik van die woord.

(3) Die verbinding diakonos tês ekklesias, diaken van die gemeente, plaas Phoebe se dienswerk buite die kader van bloot persoonlike diens, maar stel haar diakonoswees in onlosmaaklike relasie tot die gemeente: sy is diakonos van en vir die gemeente van Jesus Christus!

Terwyl Ridderbos nog in sy Kommentaar op Romeine in 1959 heel terughoudend is oor die betekenis van diakonos hier (Commentaar op het Nieuwe Testament, 1959), is hy in 1967 in sy De pastorale Brieven hieromtrent baie beslis: ". . ook in Rom 16:1 wordt van een vrouwelijke diaken gesproken" (p 99; vgl ook Anders Nygren, Commentary on the Romans, 1967; Otto Michel, Der Brief an die Römer, Meyer-reeks, 1966 p 377).

Ek verwys laastens nog na 1 Tm 5:3-16, veral 9-10: “Laat'n weduwee gekies word (of: laat as weduwee ingeskryf word), nie minder as sestig jaar nie, wat die vrou van een man gewees het, en getuienis het van goeie werke, as sy kinders grootgemaak het, gasvry gewees het, die voete van die heiliges gewas het, verdruktes gehelp en elke goeie werk nagestreef het."

Hierdie teks (1) kom voor geheel en al binne die konteks van die vraagstuk van die versorging van hulpbehoewende weduwees - 'n eg diakonale terrein;

(2) stem sowel in die aard van die vereistes wat gestel word vir die verkiesing (of inskrywing) van so 'n dien- 
ende weduwee, as in die formulering van die vereistes, ten nouste ooreen met I Tm 3:1-13 waar die vereistes vir ouderlinge en diakens gestel word;

(3) eis van die verkose weduwee 'n lewe vol van die gawes van liefdesdiens en daadwerklike gemeenskapsbetoon;

(4) verleen veral in die lig van die teëstelling wat in vers 16 gemaak word, duidelik 'n sterk gemeentelike, institutêre karakter aan die besondere dienswerk van die verkose weduwee;

(5) dui of (waarskynlik) op 'n besondere weduwee-amp met sterk diakonale trekke óf op 'n "gespesialiseerde" weduwee-diakenskap.

\section{Slotsom}

Terwyl nie een van die genoemde Skrifgedeeltes sonder sy eksegetiese probleme is nie, is hul gesamentlike geuienis myns insiens tog so sterk dat ons beswaarlik anders kan as om te erken dat die Skrifgetuienis dui op die wenslikheid van 'n diakenamp waarin ook vroue geroep kan word. Die aard van hierdie amp, waarin lering en regering nie voorop staan nie, maar die dienende liefdesbelewing, bied dan ook inderdaad geen verhindering vir bediening daarvan deur die vrou nie.

\section{ENKELE SLOTVRAE}

Aangesien hierdie artikel niks meer wil wees as 'n voorlopige ondersoek en 'n prikkel tot besinning nie, sluit ek af met enkele konkluderende maar ook enkele vootskreiende vrae.

5.1. Ons staan voor die feitlike situasie van die volgende dilemma: die Kerk van die Nuwe Testamentiese tyd was ten opsigte van ware vrymaking van die vrou die wêreld, die omringende maatskappy ver voor. Vandag egter is ons kerke die maatskappy ver agter. Hoe moet ons hieroor oordeel? Te meer waar onsself meedoen aan die emansipasie van die vrou in die maatskappy?

5.2. Waarom is dit dat die "vrou in die ampte" die vinnigste inslag vind in kerklike kringe waar die Skrifgesag gerelativeer word? En mag hierdie feit ons stuur in die rigting van 'n reaksionêre houding téén oorweging van die probleem? 
5.3. In hoeverre is die drukdoenery (vgl die haas daarmee in sekere Nederlandse kringe) om die vrou in die leraars- en ouderlingeampte te stel die resultaat óf van "ooramptelikheid" in die kerke, dit wil sê 'n houding asof die gelowige alleen waarlik kan dien en volwaardige lidmaat kan wees as hy/sy juis in die amp mag staan; óf van 'n gesagsmiskenning in die kerke, wat laat sê: wat is die amp nou eintlik dat dit net vir sommige gereserveer word?

5.4. Is die ernstige verskraling van die diakenamp tot "armversorging", en die gevolglike kompensasie-aksie om die diakens steeds meer aandeel aan "kerkraadsake" te gee, nie ' $n$ hoofstruikelblok in die weg van die verkiesing van begaafde susters tot hierdie amp wat moet wees: die diens van die konkrete liefdesgemeenskap in die kerk nie?

5.5. En eindelik:Kan ons dit bekostig en mag ons ons dit veroorloof om tot tyd en wyl dat ons duidelikheid gekry het oor "die vrou en die ampte", die heerlike geestesgawes wat die Heilige Gees aan susters in die Kerk bedeel, prakties op non-aktiwiteit te hou?

Of moet ons ernstig en dringend besin oor weë en kanale wat onder amptelike leiding en aanmoediging geskep moet word vir die uitlewing van hierdie gawes tot opbou van die Kerk van Jesus Christus?

J C COETZEE

PU vir CHO 